\title{
Susceptibility to SARS, MERS, and COVID-19 from animal health perspective
}

\author{
Aasish Gautam ${ }^{1 *}$, Krishna Kaphle ${ }^{2}$, Birendra Shrestha ${ }^{1}$ and Samiksha Phuyal ${ }^{1}$ \\ ${ }^{1}$ Institute of Agriculture and Animal Science, Tribhuvan University, Rupandehi, Nepal \\ ${ }^{2}$ Veterinary Teaching Hospital, Institute of Agriculture and Animal Science, Tribhuvan University, Rupandehi, Nepal
}

\begin{abstract}
Viruses are having great time as they seem to have bogged humans down. Severe acute respiratory syndrome (SARS), Middle East respiratory syndrome (MERS), and novel coronavirus (COVID-19) are the three major coronaviruses of present-day global human and animal health concern. COVID-19 caused by SARS-CoV-2 is identified as the newest disease, presumably of bat origin. Different theories on the evolution of viruses are in circulation, yet there is no denying the fact that the animal source is the skeleton. The whole world is witnessing the terror of the COVID-19 pandemic that is following the same path of SARS and MERS, and seems to be more severe. In addition to humans, several species of animals are reported to have been infected with these life-threatening viruses. The possible routes of transmission and their zoonotic potentialities are the subjects of intense research. This review article aims to overview the link of all these three deadly coronaviruses among animals along with their phylogenic evolution and cross-species transmission. This is essential since animals as pets or food are said to pose some risk, and their better understanding is a must in order to prepare a possible plan for future havoc in both human and animal health. Although COVID-19 is causing a human health hazard globally, its reporting in animals are limited compared to SARS and MERS. Non-human primates and carnivores are most susceptible to SARS-coronavirus and SARS-CoV-2, respectively, whereas the dromedary camel is susceptible to MERS-coronavirus. Phylogenetically, the trio viruses are reported to have originated from bats and have special capacity to undergo mutation and genomic recombination in order to infect humans through its reservoir or replication host. However, it is difficult to analyze how the genomic pattern of coronaviruses occurs. Thus, increased possibility of new virus-variants infecting humans and animals in the upcoming days seems to be the biggest challenge for the future of the world. One health approach is portrayed as our best way ahead, and understanding the animal dimension will go a long way in formulating such preparedness plans.
\end{abstract}

Keywords: Animal health, COVID-19, Cross-species, One health, Trio coronaviruses.

\section{Introduction}

Newercoronaviruses(CoVs) continue to be detected from various wildlife species, most notably the bat (Valitutto et al., 2020). It is a fact that humans and their interaction with wildlife is on an increasing frequency. CoVs infect a variety of animal species causing respiratory, hepatic, enteric, and neurological diseases of varying degrees (Woo et al., 2012). These are traditionally divided into three groups (groups I, II, and III) based on their serological and genomic characterization (Brian and Baric, 2005). The International Committee on Taxonomy of Viruses proposed replacing the genera for these traditional groups, namely $\alpha$-coronavirus, $\beta$-coronavirus, and $\gamma$-coronavirus for group I, II, and III, respectively (Woo et al., 2012). Currently, the new genera $\delta$-coronavirus is also grouped; hence, coronaviruses are grouped under four different genera, including severe acute respiratory syndrome (SARS) and Middle East respiratory syndrome (MERS; Xu et al., 2016). These genera and viruses possess special characteristics to undergo mutation in order to infect a new host and have the capacity to adapt to a new ecological niche (Woo et al., 2012). Thus, understanding these viruses in animals, the eco niche, the mechanism of mutation, and how they spread to other species will be crucial in managing pandemic risks. Research studies have been narrowed down to $\alpha$ - and $\beta$-coronaviruses that have originated from the host bats serving as an ancestral origin for mammalian CoVs (Woo et al., 2012). In November 2002, a new type of virus was identified in Guangdong Province of Southern China named SARSCoV. By the end of the epidemic, around 8,437 human cases with case fatality of $9 \%$ was detected (Peeri et al., 2020; Fig. 1). These viruses were isolated from the palm civet and other game-food mammals in June, 2003 with 98.8\% nucleotide similarity to SARS-CoV (Cheng et al., 2007). Subsequently, research studies identified the SARS-like coronavirus (SL-CoV) in horseshoe bats acting as a reservoir host and SARS-CoV in several carnivores (civet and raccoon dog) from the Chinese wet market (Bolles et al., 2011; Ge et al., 2013) acting as a replication host (Guan et al., 2003). After SARS, MERS reportedly evolved causing a global health threat in 2012 originating from Saudi Arabia (Mackay and Arden, 2015). Various studies have shown bats as a reservoir host for MERS-CoV since the HKU4 of

*Corresponding Author: Aasish Gautam. Institute of Agriculture and Animal Science, Tribhuvan University, Rupandehi, Nepal. 


\section{Case Fatality of Coronavirus}

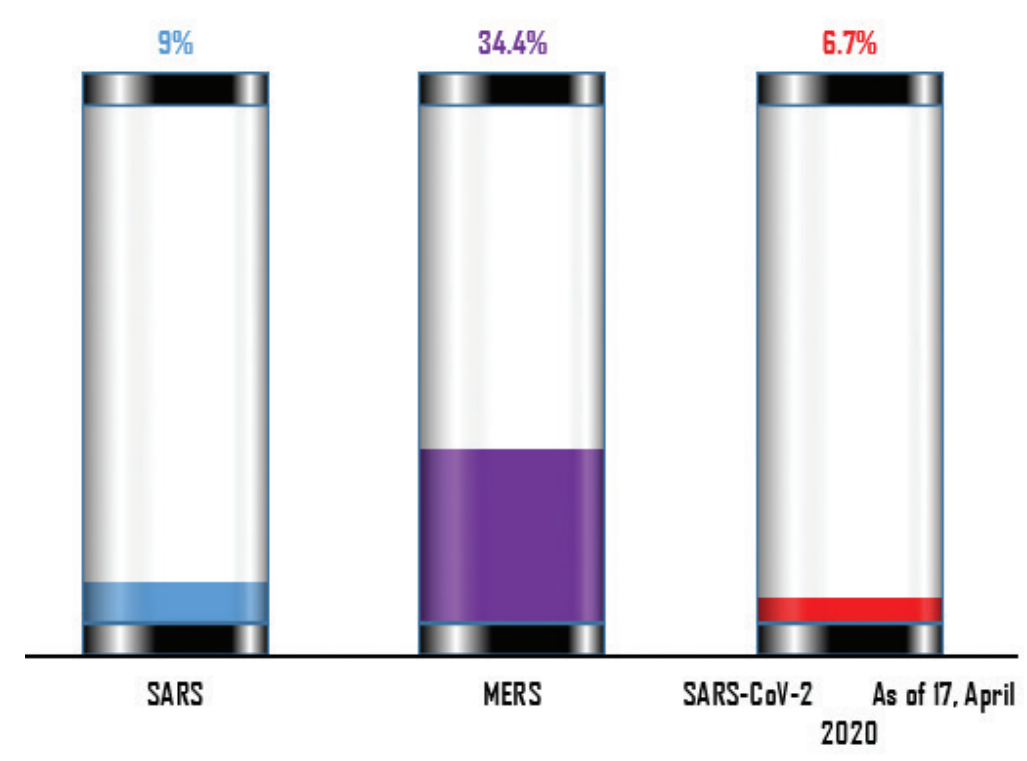

Fig. 1. Comparison of case fatalities in SARS, MERS, and SARS-CoV-2 as of 17 April 2020. It shows highest case fatality for MERS-CoV.

bats resembeled MERS-CoV genetically (Annan et al., 2013), but alpacas can also act as a potential reservoir for MERS (Mohd et al., 2016). Hemida et al., (2013) reported the genome of human origin MERS-CoV being 99.9\% similar to the genome of MERS-CoV affecting dromedaries. It is still unclear how the dromedary camels got infected by MERS-CoV; however, a recent study also supports that MERS-CoV jumped from bats to camels in Africa some 20 years ago and these camels were reportedly imported to the Arabian Peninsula (Corman et al., 2014). Since 2012, around 2,494 health cases of MERS have been reported with $34.4 \%$ case fatality (Al-Omari et al., 2019; Fig. 1).

The novel coronavirus (COVID-19) epidemic is the current concern and is reported to have been detected in later part of the year 2019, hence, named from the wet market in Wuhan city in China. Various opinions on the origin of the virus is in discussion, including the theory of engineered virus spillage. The etiological agent for COVID-19 is SARS-CoV-2 (Tang et al., 2020). The virus is phylogenetically originated from bats (Cui et al., 2019; Li et al., 2020). The recent findings postulated that the SARS-CoV was genetically similar to bat-CoV of subgenus Sarbecovirus (Wu et al., 2020; Xu et al., 2020). Thus, the identified genome of COVID-19 has a $96.2 \%$ genomic similarity to bat-CoV (RaTG13) in China (Zhou et al., 2020), but has around $79 \%$ and $50 \%$ genomic similarity to SARS-CoV and MERS-CoV, respectively (Lu et al., 2020). Anteaters and snakes are also reported to be possible reservoirs for COVID-19 (Ji et al., 2020). COVID-19's spread is happening globally at this moment, and around 2.2 million counting humans have tested positive with fatality of $6.7 \%$ detected since its outbreak until April 17, 2020 (WHO, 2020; Fig. 1). In addition to humans, several animals like cats, dogs, and tigers also tested positive, but no animal to animal or animal to human transmission is reported. The objective of this review article is to summarize all the deadly coronaviruses reported from animals and their possible cross-species transmission pattern along with phylogenetic modification. The objective is to present a concise and updated article for the growing attention on, interest in, and focus on this topic.

\section{SARS-CoV}

\section{Phylogenic Modification}

SARS appeared for the first time in 2002 in Guangdong Province, Southern China ( $\mathrm{Hu}$ et al., 2015). After its emergence, SARS-CoV was confirmed in palm civets and horseshoe bats from the wet market in Guangdong Province, as reservoirs of SARS-CoV (Luk et al., 2019). Before the appearance of SARS, around $10 \mathrm{CoVs}$ genome sequences were available and placed into three groups, namely groups I, II, and III. However, later the International Committee on Taxonomy of Viruses announced three genera for these groups, namely alphacoronavirus, betacoronavirus, and gammacoronavirus (de Groot et al., 2011). The discovery of SARS-CoV in 2003 and its phylogenic evidence placed SARS-CoV into the betacoronavirus, and subsequently, into the subgenus Sarbecovirus (Luk et al., 2019). Among these coronaviruses, the alpha and 
beta mainly infect mammals, and the assigned species (almost 7 out of 15) of viruses were reported in bats (de Groot et al., 2011). Hence, it is proposed that bats are an important source in the evolutionary analysis (Woo et al., 2012). Phylogenic modification of $16 \mathrm{BO} 133$ strain of the bat coronavirus is placed in beta-CoV lineage which is closely related to the JTMC15 strain of the horseshoe bat (Rhinolophus ferrumequinum) isolated in China (Kim et al., 2019).

MERS-CoV

Middle East respiratory syndrome (MERS) was classified into the family coronaviridae, subfamily coronavirinae, and genus betacoronavirus (Bayrakdar et al., 2015). The closest ancestors of MERS-CoV, namely SARS$\mathrm{CoV}$ and human CoV-229E, phylogenetically evolved through the Vespertilionidae (insectivorous bat) family and belong to Neoromicia and Pipistrellus (Annan et al., 2013). The Tylonycteris bat coronavirus HKU4 (TyBatCoV HKU4) and Pipistrellus bat coronavirus (PiBatCoV HKU5) genomes of bat resemble with MERS$\mathrm{CoV}$, hence, considered as a reservoir host, but alpacas also act as a potential reservoir for MERS-CoV (Mohd et al.,2016. The first report of MERS identified it as a novel betacoronavirus (MERS-CoV) (Zaki et al., 2012). The evolutionary history of MERS-CoV reported its evolution through a genetic recombination of MERS-CoV clade A and B (Wang et al., 2015). This genomic recombination occurred in two groups (groups III and V) among the five phylogenic groups of clade B (Wang et al., 2015).

\section{SARS-CoV-2}

Belonging to family Coronaviridae and genus $\beta$-coronavirus, SARS-CoV-2 shares a similar genetic make-up with Bat-CoV (RaTG13/Beta-CoV) and an almost similar make-up with snakes; hence, considered as a reservoir for COVID-19 (nCoV; Ji et al., 2020; Zhang et al., 2020). Convergent evolution through homologous recombination between this virus and a virus of unknown origin makes it different from the coronavirus of human origin (Ji et al., 2020; Sun et al., 2020). SARS-CoV-2 shares almost a $91.02 \%$ character similarity to pangolin-CoV and $90.55 \%$ with RaTG13 (Zhang et al., 2020). But the difference in the neutral site of RaTG13 and SARS-CoV-2 is almost 17\%, suggesting a much larger divergence between these two viruses than previous estimated study (Tang et al., 2020). The developing variation is due to the variation raised in the Ras-binding domain of the glycoprotein spike, which acts as an angiotensin-converting enzyme-2 (ACE-2), and the genetic mutation of pangolin SARS-CoV is most likely a genetic recombination (Tang et al., 2020). The evolutionary tree indicates that SARS-CoV-2 is closer to RaTG13, followed by the pangolin SARSCoV (Tang et al., 2020).

\section{SARS-CoV}

\section{Susceptibility in Animal Species}

In addition to reservoir (horseshoe bat) and replication intermediate (Himalayan palm civet and raccoon dog) hosts, various non-human primates are liable to be infected, causing a fever and quite, mildly labored breathing in aged animals (Smits et al., 2010). The susceptibility of various species with SARS-CoV is shown Table 1.

MERS-CoV

The life-threatening diseases of humans somehow have possible links with the animal species. MERS, although recognized as a disease of the dromedary camels, causes asymptomatic or mild respiratory distress (Hemida et al., 2014), mild fever, and rhinorrhea (Adney et al., 2014). Various other animal species are also found susceptible to MERS-CoV (Table 2). The virus causes mild respiratory problems (respiratory discharges, coughing, sneezing), fever, and loss of appetite in animals (Hemida et al., 2014).

\section{COVID-19 (SARS-CoV-2)}

The following questions were unknown to scientists during the SARS-CoV-2 pandemic: Does the virus infect animals as well as humans? If yes, what types of animals are more susceptible? Does the virus transmit from animals to humans? At the same time, a report from Hong Kong showed that one Pomeranian tested weakly positive, after which one German shepherd tested positive to SARS-CoV-2 (Cohut, 2020). A report from Belgium also reported SARS-CoV-2 in cats (Jeanna, 2020a). These reports suggest the chance of transmission of SARS-CoV-2 from humans to animals. Because of the contradictory information regarding the possibility of transmission of SARS-CoV-2 in animals, scientists from Harbin Veterinary Research Institute, Chinese Academy of Agricultural Sciences, and the National High Containment Laboratory for Animal Diseases Control and Prevention gathered together and analyzed its susceptibility in different animals. They concluded that cats and ferrets are the most susceptible to SARS-CoV-2 infections, but virus multiplication in dogs, pigs, chickens, and ducks are poor, and there was no intraspecies and interspecies transmission of SARS-CoV-2 from dogs, pigs, chickens, and ducks (Shi et al., 2020; Table 3). Wild animals are also susceptible to SARS-CoV-2. The US Wildlife Conservation Society announced on April 5, 2020, cases in a 4-year-old female Malayan tiger together with her sister, two Amur tigers, and three African lions (Jeanna, 2020b).

Bats are supposed to be the natural reservoir for the SARS-CoV-2 because the virus shares a 96\% genomic identity to the bat coronavirus and their protein sequence shares a similarity to SARS-CoV (Zhou et al., 2020). Recent findings that analyze the probable animal reservoir to COVID-19 suggest the snake as a reservoir, based on relative synonymous codon usage (RSCU) bias (Ji et al., 2020). The missing link or intermediate link for animal to human transmission of SARS-CoV-2 from a recent study suggests the DNA and protein sequence of Malayan pangolins (Zhang et al., 2020). 


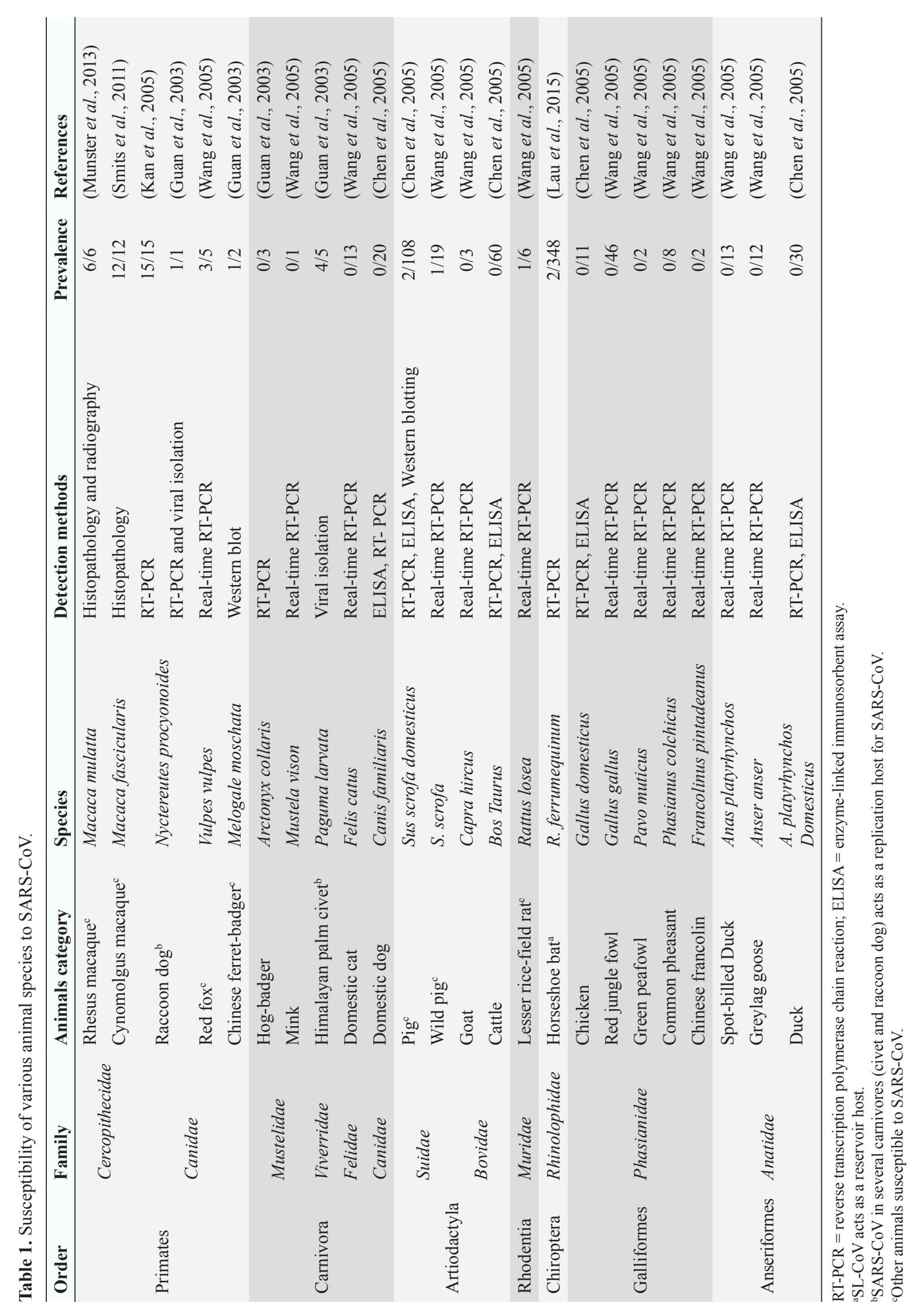




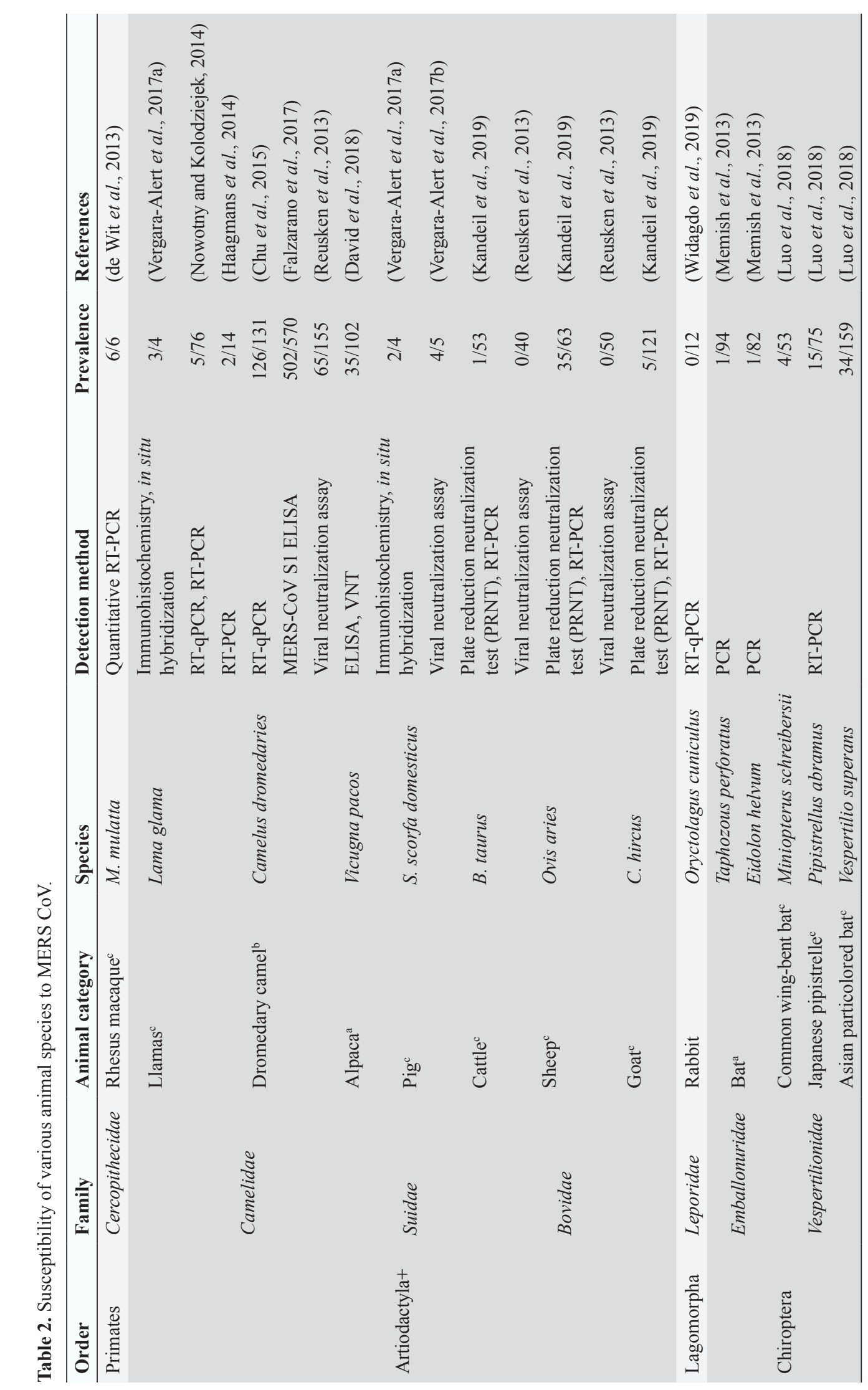



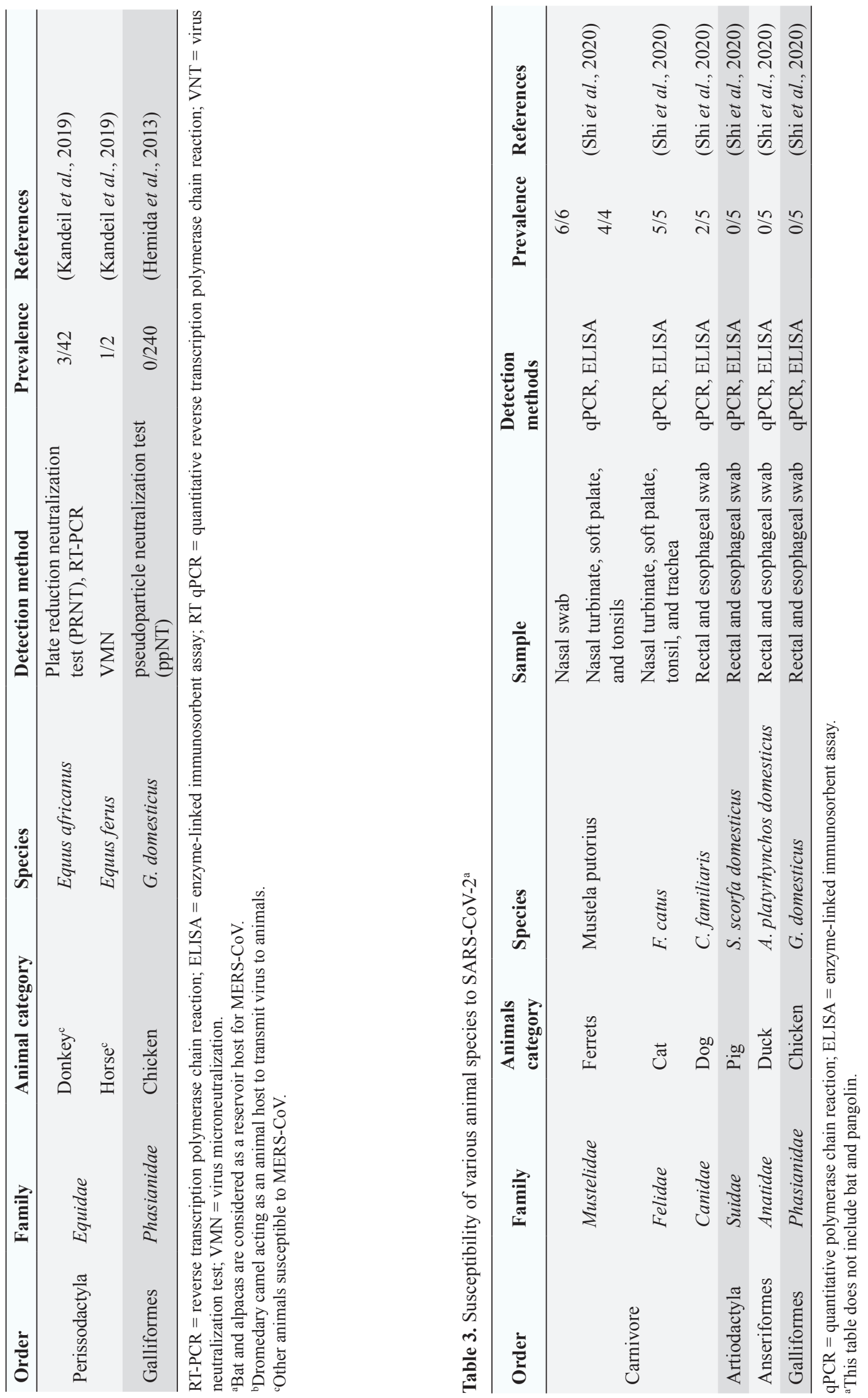


\section{SARS-CoV}

\section{Cross-Species Transmission}

A unique virus was isolated from the palm civet and other game-food mammals in June, 2003, with 98.8\% nucleotide similarity to SARS-CoV (Cheng et al., 2007). Subsequently, research studies have identified SL-CoV in horseshoe bat acting as a reservoir host, and SARS$\mathrm{CoV}$ in several carnivores (civet and raccoon dog) from the Chinese wet market (Bolles et al., 2011; Ge et al., 2013) acting as a replication host (Guan et al., 2003; Fig. 2). Later, one asymptomatic and four symptomatic cases of SARS were reported from December 16, 2003 to January 8, 2004 in Guangdong Province, China, which were similar to SARS-CoV of animal origin (Cheng et al., 2007). Chen et al. (2005) reported the transmission of SARS-CoV of human origin to pigs. Ge et al. (2013) provided the solid evidence of horseshoe bats acting as a reservior host and the virus acting as a cellular receptor ACE-2 in both bats and humans. The analysis of spike glycoprotein for receptor ACE-2 indicated that amino acid 487 was responsible for the spike ACE-2 interaction. Its mutation appeared to be responsible for the human to human transmission of SARS-CoV (Li et al., 2005).

\section{MERS-CoV}

Various studies have shown bats as a reservior host for MERS-CoV since the HKU4 of bats resembeled

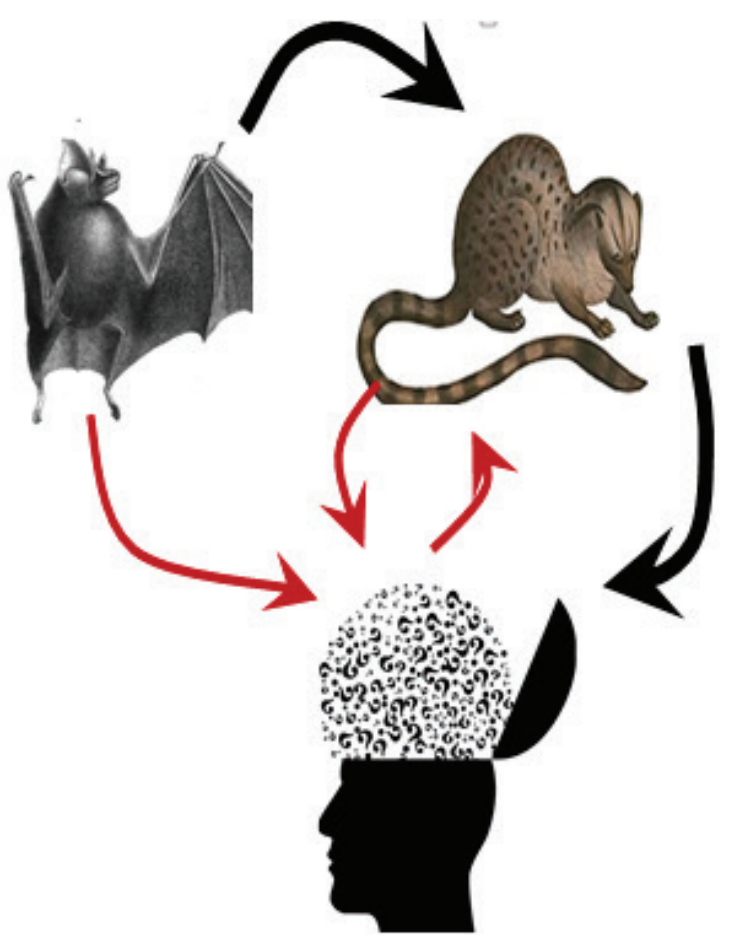

Fig. 2. The summarized information suggests that bats acted as a reservoir host for SARS-CoV, and initially jumped to palm civet and subsequently into humans (black arrows). Phylogenetic study suggested direct transmission from bats to humans and possible cross-transmission between palm civet and humans (red arrows).
MERS-CoV genetically (Annan et al., 2013), but alpacas also act as a potential reservior for MERS (Mohd et al., 2016). Humans get infected when MERS$\mathrm{CoV}$ spike attaches to the dipeptidyl peptidase 4 (DPP4) of the human receptor. Both HKU4 and MERSCoV are attached to the DPP4 receptor, but the HKU4 requires the host endogenous protesase for activation in humans, and only MERS-CoV can mediate its entry into the human cell (Yang et al., 2014). But the mutation of HKU4 in S246R and N762A possesses a special capacity to enter inside the human cell receptor (Yang et al., 2015). A two-fold mutation of HKU4 adaptive for its attachement to the endogenous cellular protease supports the role of bats in the transmission cycle either directly or by amplyfying the host in humans (Yang et al., 2015). Hemida et al. (2014) reported that the genome of human origin MERS-CoV is $99.9 \%$ similar to the genome of MERS-CoV afffecting the dromedary camels. It is still unclear how the dromedary camels got infected with MERS-CoV; but a recent study supports that MERS-CoV jumped to the camel from bat-CoV in Africa 20 years ago and these camels from Africa were imported to the Arabian Peninsula (Corman et al., 2014). The evidence of the transmission of MERS$\mathrm{CoV}$ from dromedary camels to humans was reported in October 2013 in Qatar (Haagmans et al., 2014) and in November 2013 in Saudi Arabia (Azhar et al., 2014). These findings also support the possible infection in humans through dromedary camels (Fig. 3).

\section{SARS-CoV-2}

Bats are supposed to be the natural reservoir of the SARS-CoV-2 since they share a $96 \%$ genomic identity with bat coronavirus and their protein sequence shares a similarity to SARS-CoV (Zhou et al., 2020). However,

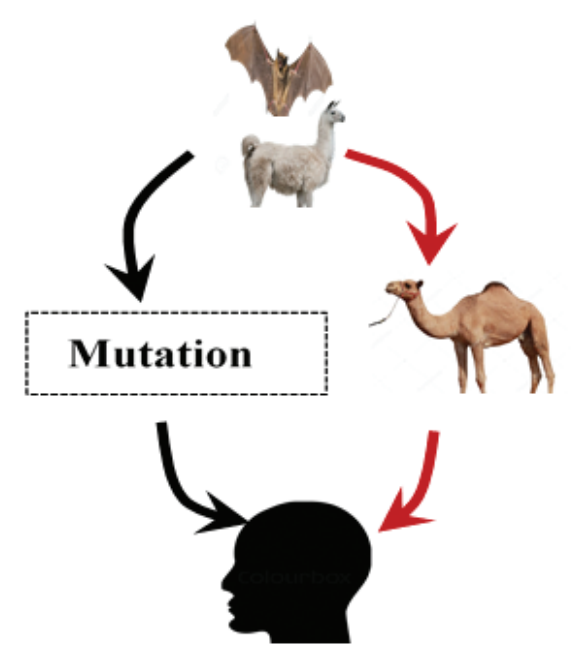

Fig. 3. Bat and alpacas are considered as a reservoir host for MERS-CoV. Dromedary camel acting as an animal host to transmit virus to animals (red arrows). But recent studies show the mutation of the MERS-CoV spike of reservoir host in bat to human transmission (black arrows). 
snakes are the recently reported possible reservoirs for COVID-19 (Ji et al., 2020). In humans, COVID-19 is developed from a homologous recombination of cell surface receptors recognizing the glycoprotein spike of the bat virus and a new virus of unknown origin ( $\mathrm{Ji}$ et al., 2020). This homologous recombination of the glycoprotein spike in bats and snakes contributes to the cross-species transmission from animals to humans (Ji et al., 2020) (Fig. 4). A recent study reported that the DNA and protein sequence of Malayan pangolins share a $91.02 \%$ similarity to SARS-CoV-2, acting as an intermediate link or missing link for cross-species transmission (Zhang et al, 2020). Cats are also susceptible to SARS-CoV-2, since the cellular receptor ACE2 protein for entry of SARS-CoV-2 in humans resembles the feline homologue ACE2 (Jeanna, 2020a). The information on the cross-transmission model of SARS CoV-2 is still contradictory; however, a previous study on SARS-CoV showed possible transmission of SARS-virus from infected cats to humans (Martina et al., 2003). A team of virologist, led by Bu Zhigao, reported on intraspecies transmission of SARS-CoV-2 in cats through respiratory droplets, but the actual mode of transmission in those cats is unclear; however, it could be through the virus secreted in the urine or feces (Mallapaty, 2020a, 2020b). Steven Van Gucht, a virologist from Belgium, told Live Science the possible interspecies transmission of COVID-19 from humans to cats because a week after the owner got sick the cat tested positive (Jeanna, 2020a). Virologist Linda Saif says there is no direct evidence that the coronavirus in the secretion of cats infects humans (Mallapaty,

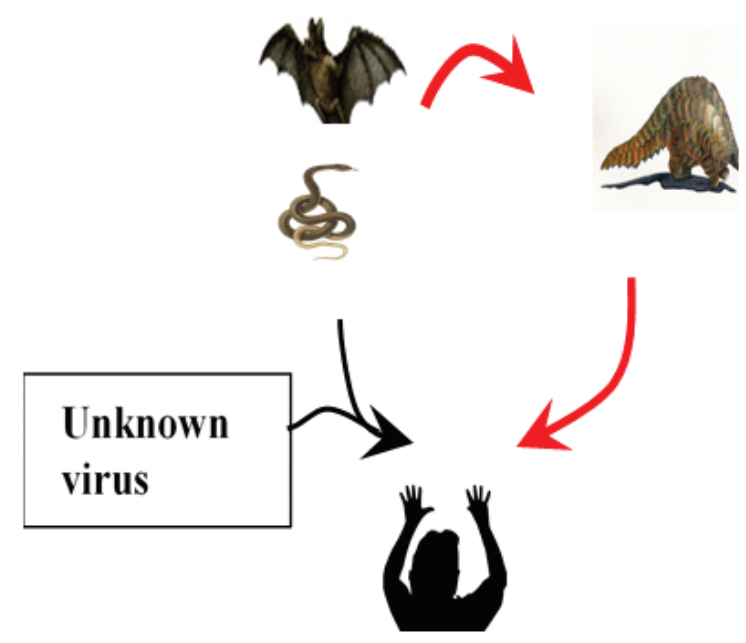

Fig. 4. A recent report showed bats and snakes acting as reservoirs for SARS-CoV-2 and Malayan pangolin as a jumping link (red arrows). Humans get infected either from the recombination of the reservoir host virus with an unknown virus (black arrows) or from the intermediate link (red arrows). 2020b). Shi et al. (2020) reported no intraspecies and interspecies transmission of COVID-19 from dogs, pigs, chickens, and ducks.

\section{Conclusion}

Bats cause various life-threatening diseases in both animal- and human-like SARS (SARS-CoV), MERS (MERS-CoV), Ebola virus, Nipah virus, Hendra virus, and Murburg virus (Han et al., 2015). Recently, COVID-19 caused by SARS-CoV-2 was identified as a newest disease of bat origin (Zhou et al., 2020). Research studies have identified SL-CoV in horseshoe bats and palm civets from the Chinese wet market named SARS-CoV (Bolles et al., 2011; Ge et al., 2013). Horseshoe bats act as a reservoir for this virus, but it is difficult to understand this characteristic properly in wild animals because of their genetic diversity. Moreover, other animals, like the red fox, Chinese ferret-badger, pig, wild pig, and lesser field rats, are also susceptible to SARS-CoV (Table 1 and Fig. 5). MERS caused by MERS-CoV originated in Saudi Arabia, a direct ancestor of SARS-CoV, also originated from bats (Annan et al., 2013). In addition to bats, alpacas also act as a potential reservoir for MERS-CoV, and the dromedary camels act as a host to transmit virus to humans (Table 2), since MERS-CoV spike is attached to the DPP4 human receptor (Yang et al., 2014). Other animals, like the rhesus macaque, llamas, pig, cattle, sheep, goat, donkey, and horse, are also susceptible to MERS-CoV (Table 2 and Fig. 5).

The novel outbreak causing respiratory illness in global human health is caused by COVID-19 (SARSCoV-2; Peeri et al., 2020). Bats are common ancestors

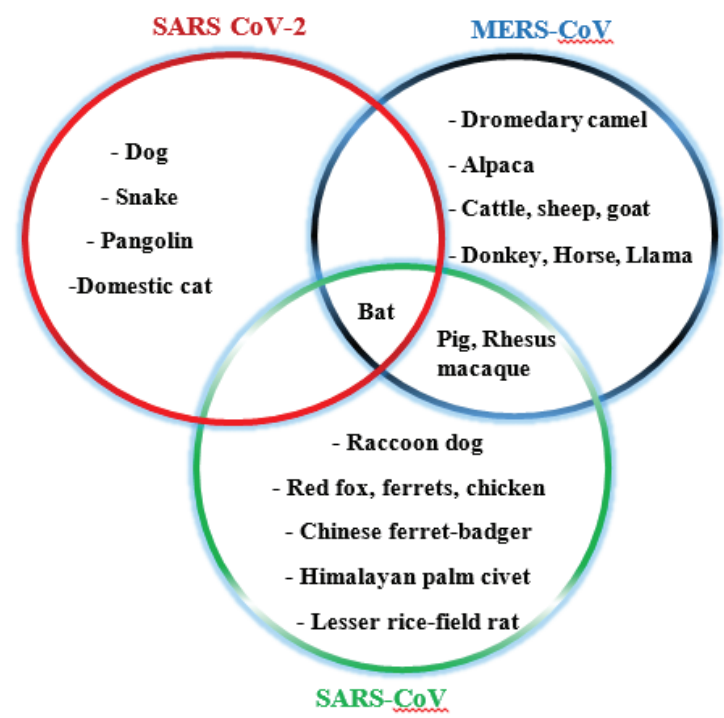

Fig. 5. Various animal species susceptible to coronaviruses. It shows that bats are common for all, acting as a reservoir host. 


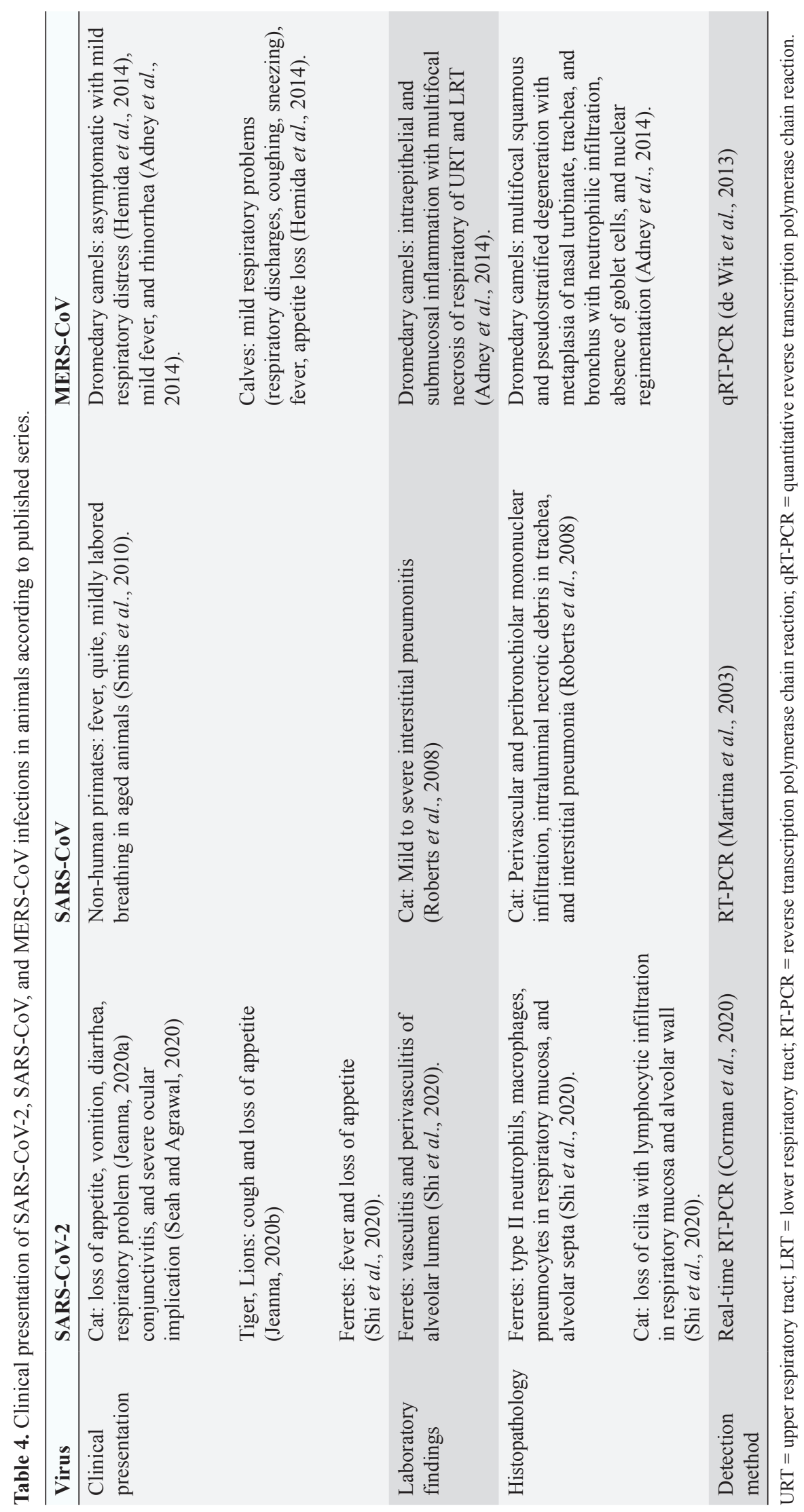


for all the deadly coronaviruses. SARS-CoV-2 also shares a $96 \%$ genomic similarity to bat-CoV (Ji et al., 2020). Hence, bats act as a reservoir for COVID-19. The virus also has characteristics to undergo genomic recombination as SARS-CoV between glycoprotein spike of the bat virus and a virus of unknown origin. The recombinant virus of SARS-CoV-2 and SARS$\mathrm{CoV}$ acts on the ACE-2 receptor of humans (Jeanna, 2020a). In addition to humans, animals, like cats and ferrets, are also most susceptible to SARS-CoV-2, but its multiplication in dogs, pigs, chickens, and ducks are poor (Shi et al., 2020; Table 3 and Fig. 5). Clinical presentation, laboratory findings, histopathology, and detection methods of SARS-CoV-2, SARS-CoV, and MERS-CoV infections in animals according to the published series are presented in Table 4. It is very difficult to understand how the genomic pattern occurs among these coronaviruses, in order to make an effective plan for control and prevention. There is increased possibility of new virus-variants infecting animals and humans in the upcoming days which seems to be the biggest challenge for the future of the world.

\section{Conflict of interest}

The authors declare that there is no conflict of interest.

\section{References}

Adney, D.R., Doremalen, N. Van, Brown, V.R., Bushmaker, T., Scott, D., Wit, E. de, Bowen, R.A., Munster, V.J. 2014. Replication and shedding of MERS-CoV in upper respiratory tract of inoculated dromedary camels. Emerg. Infect. Dis. 20, 19992005.

Al-Omari, A., Rabaan, A.A., Salih, S., Al-Tawfiq, J.A., Memish, Z.A. 2019. MERS coronavirus outbreak: implications for emerging viral infections. Diagn. Microbiol. Infect. Dis. 93, 265-285; doi:10.1016/j. diagmicrobio.2018.10.011.

Annan, A., Baldwin, H.J., Corman, V.M., Klose, S.M., Owusu, M., Nkrumah, E.E., Badu, E.K., Anti, P., Agbenyega, O., Meyer, B., Oppong, S., Sarkodie, Y.A., Kalko, E.K. V, Lina, P.H.C., Godlevska, E. V, Reusken, C., Seebens, A., Gloza-rausch, F., Vallo, P., Tschapka, M., Drosten, C., Drexler, J.F. 2013. Human betacoronavirus 2c EMC/2012-related viruses in Bats, Ghana and Europe. Emerg. Infect. Dis. $19,456-459$.

Azhar, E.I., El-kafrawy, S.A., Farraj, S.A., Hassan, A.M., Al-saeed, M.S., Hashem, A.M., Madani, T.A. 2014. Evidence for camel-to-human transmission of MERS coronavirus. N. Engl. J. Med. 370, 2499 2505; doi:10.1056/NEJMoa1401505

Bayrakdar, F., Altaş, A.B., Korukluoğlu, G., Topal, S. 2015. Molecular diagnosis and phylogenetic analysis of the first MERS case in Turkey. Mikrobiyol. Bul. 49, 414-442.

Bolles, M., Donaldson, E., Baric, R. 2011. SARS-CoV and emergent coronaviruses: viral determinants of interspecies transmission. Curr. Opin. Virol. 1, 624-634; doi:10.1016/j.coviro.2011.10.012.

Brian, D.A., Baric, R.S. 2005. Coronavirus genome structure and replication. Curr. Top. Microbiol. Immunol. 287, 1-30; doi:10.1007/3-540-267654 . 1 .

Chen, W., Yan, M., Yang, L., Ding, B., He, B., Wang, Y., Liu, X., Liu, C., Zhu, H., You, B., Huang, S., Zhang, J., Mu, F., Xiang, Z., Feng, X., Wen, J., Fang, J., Yu, J., Yang, H., Wang, J. 2005. SARSassociated transmitted from coronavirus human to pig. Emerg. Infect. Dis. 11, 446-448; doi:10.3201/ eid1103.040824.

Cheng, V.C.C., Lau, S.K.P., Woo, P.C.Y., Kwok, Y.Y. 2007. Severe acute respiratory syndrome coronavirus as an agent of emerging and reemerging infection. Clin. Microbiol. Rev. 20, 660-694; doi:10.1128/CMR.00023-07.

Chu, D.K., Oladipo, J.O., Perera, R.A., Kuranga, S.A., Chan, S.M., Poon, L.L., Peiris, M. 2015. Middle East respiratory syndrome coronavirus (MERS$\mathrm{CoV}$ ) in dromedary camels in Nigeria, 2015. Euro Surveill. 20, 30086; doi:10.2807/1560-7917. ES.2015.20.49.30086.

Cohut, M. 2020. Cats may be able to contract SARS-CoV-2, but evidence is limited. MEDICALNEWSTODAY. Available via https:// www.medicalnewstoday.com/articles/cats-maybe-able-to-contract-sars-cov-2-but-evidence-islimited (Accessed 6 April 2020).

Corman, V.M., Ithete, N.L., Richards, R., Schoeman, M.C., Preiser, W., Drosten, C., Drexler, J.F. 2014. Rooting the phylogenetic tree of middle east respiratory syndrome coronavirus by characterization of a conspecific virus from an African bat. J. Virol. 88, 11297-11303; doi:10.1128/ JVI.01498-14

Corman, V.M., Landt, O., Kaiser, M., Molenkamp, R., Meijer, A., Chu, D.K.W., Bleicker, T., Schneider, J., Schmidt, M.L., Mulders, D.G.J.C., Haagmans, B.L., Veer, B. Van Der, Den, S. Van, Wijsman, L., Goderski, G., Ellis, J., Zambon, M., Peiris, M., Goossens, H., Reusken, C., Koopmans, M.P.G., Drosten, C. 2020. Detection of 2019 novel coronavirus (2019-nCoV) by real-time RT-PCR. Euro Surveill. 25, 2000045.

Cui, J., Li, F., Shi, Z.-L. 2019. Origin and evolution of pathogenic coronaviruses. Nat. Rev. Microbiol. 17, 181-192; doi:10.1038/s41579-018-0118-9

David, D., Rotenberg, D., Khinich, E., Erster, O., Bardenstein, S., van Straten, M., Okba, N.M.A., Raj, S. V., Haagmans, B.L., Miculitzki, M., Davidson, I. 2018. Middle East respiratory syndrome coronavirus specific antibodies in naturally exposed Israeli llamas, alpacas and camels. One Heal. 5, 6568; doi:10.1016/j.onehlt.2018.05.002. 
de Groot, R.J., Baker, S.C., Baric, R., Enjuanes, L., Gorbalenya, A., Holmes, K.V., Perlman, S., Poon, L., Rottier, P.J., Talbot, P.J., Woo, P.C., Ziebuhr, J. 2011. Coronaviridae. In Virus taxonomy, classification and nomenclature of viruses. Ninth report of the international committee on taxonomy of viruses, International Union of Microbiological Societies, Virology Division. Cambridge, MA: Elsevier Academic Press.

de Wit, E., Rasmussen, A.L., Falzarano, D., Bushmaker, T., Feldmann, F., Brining, D.L., Fischer, E.R., Martellaro, C., Okumura, A., Chang, J., Scott, D., Benecke, A.G., Katze, M.G., Feldmann, H., Munster, V.J. 2013. Middle East respiratory syndrome coronavirus (MERSCoV) causes transient lower respiratory tract infection in rhesus macaques. Proc. Natl. Acad. Sci. 110, 1659816603; doi:10.1073/pnas.1310744110.

Falzarano, D., Kamissoko, B., de Wit, E., Maïga, O., Cronin, J., Samaké, K., Traoré, A., Milne-Price, S., Munster, V.J., Sogoba, N., Niang, M., Safronetz, D., Feldmann, H. 2017. Dromedary camels in northern Mali have high seropositivity to MERS-CoV. One Heal. 3, 41-43; doi:10.1016/j.onehlt.2017.03.003.

Ge, X., Li, J., Yang, X., Chmura, A.A., Zhu, G., Epstein, J.H., Mazet, J.K., Hu, B., Zhang, W., Peng, C., Zhang, Y., Luo, C., Tan, B., Wang, N., Zhu, Y., Crameri, G., Zhang, S., Wang, L., Daszak, P., Shi, Z. 2013. Isolation and characterization of a bat SARS-like coronavirus that uses the ACE2 receptor. Nature 503, 535-538; doi:10.1038/nature12711.

Guan, Y., Zheng, B.J., He, Y.Q., Liu, X.L., Zhuang, Z.X., Cheung, C.L., Luo, S.W., Li, P.H., Zhang, L.J., Guan, Y.J., Butt, K.M., Wong, K.L., Chan, K.W., Lim, W., Shortridge, K.F., Yuen, K.Y., Peiris, J.S.M., Poon, L.L.M. 2003. Isolation and characterization of viruses related to the SARS coronavirus from animals in Southern China. Science 302, 276-278; doi:10.1126/science.1087139.

Haagmans, B.L., Al Dhahiry, S.H.S., Reusken, C.B.E.M., Raj, V.S., Galiano, M., Myers, R., Godeke, G.J., Jonges, M., Farag, E., Diab, A., Ghobashy, H., Alhajri, F., Al-Thani, M., Al-Marri, S.A., Al Romaihi, H.E., Al Khal, A., Bermingham, A., Osterhaus, A.D.M.E., AlHajri, M.M., Koopmans, M.P.G. 2014. Middle East respiratory syndrome coronavirus in dromedary camels: an outbreak investigation. Lancet Infect. Dis. 14, 140145; doi:10.1016/S1473-3099(13)70690-X.

Han, H., Wen, H., Zhou, C., Chen, F., Luo, L., Liu, J., Yu, X. 2015. Bats as reservoirs of severe emerging infectious diseases. Virus Res. 205, 1-6; doi:10.1016/j.virusres.2015.05.006.

Hemida, M.G., Chu, D.K., Poon, L.L., Perera, R.A., Alhammadi, M.A., Ng, H.Y., Siu, L.Y., Guan, Y., Alnaeem, A., Peiris, M. 2014. MERS coronavirus in dromedary camel herd, Saudi Arabia. Emerg. Infect. Dis. 20, 1231-1234.

Hemida, M.G., Perera, R.A., Wang, P., Alhammadi, M.A., Siu, L.Y., Li, M., Poon, L.L., Saif, L., Alnaeem,A., Peiris, M. 2013. Middle east respiratory syndrome (MERS) coronavirus seroprevalence in domestic livestock in Saudi Arabia, 2010 to 2013. Euro Surveill. 18, 20659; doi:10.2807/1560-7917. ES2013.18.50.20659.

Hu, B., Ge, X., Wang, L., Shi, Z. 2015. Bat origin of human coronaviruses. Virol. J. 12, 221; doi:10.1186/ s12985-015-0422-1.

Jeanna, B. 2020a. Cat infected with COVID-19 from owner in Belgium. Live Sci. Available via https:// www.livescience.com/cat-infected-covid-19-fromowner.html (Accessed 6 April 2020).

Jeanna, B. 2020b. Bronx Zoo tiger infected with COVID-19. Live Sci. Available via https://www. livescience.com/tiger-bronx-zoo-has-covid-19. html (Accessed 6 April 2020).

Ji, W., Wang, W., Zhao, X., Zai, J., Li, X. 2020. Cross-species transmission of the newly identified coronavirus 2019-nCoV. J. Med. Virol. 92, 433440; doi:10.1002/jmv.25682.

Kan, B., Wang, M., Jing, H., Xu, H., Jiang, X., Yan, M., Liang, W., Zheng, H., Wan, K., Liu, Q., Cui, B., Xu, Y., Zhang, E., Wang, H., Ye, J., Li, G., Li, M., Cui, Z., Qi, X., Chen, K., Du, L., Gao, K., Zhao, Y.-T., Zou, X.-Z., Feng, Y.-J., Gao, Y.-F., Hai, R., Yu, D., Guan, Y., Xu, J. 2005. Molecular evolution analysis and geographic investigation of severe acute respiratory syndrome coronaviruslike virus in palm civets at an animal market and on farms. J. Virol. 79, 11892-11900; doi:10.1128/ jvi.79.18.11892-11900.2005.

Kandeil, A., Gomaa, M., Shehata, M., El-Taweel, A., Kayed, A.E., Abiadh, A., Jrijer, J., Moatasim, Y., Kutkat, O., Bagato, O., Mahmoud, S., Mostafa, A., El-Shesheny, R., Perera, R.A.P.M., Ko, R.L.W., Hassan, N., Elsokary, B., Allal, L., Saad, A., Sobhy, H., McKenzie, P.P., Webby, R.J., Peiris, M., Ali, M.A., Kayali, G. 2019. Middle East respiratory syndrome coronavirus infection in non-camelid domestic mammals. Emerg. Microbes Infect. 8, 103-108; doi:10.1080/22221751.2018.1560235.

Kim, Y., Son, K., Kim, Y.-S., Lee, S.-Y., Jheong, W., Oem, J.-K. 2019. Complete genome analysis of a SARS - like bat coronavirus identified in the Republic of Korea. Virus Genes 55, 545-549; doi:10.1007/s11262-019-01668-w.

Lau, S.K.P., Feng, Y., Chen, H., Luk, H.K.H., Yang, W.H., Li, K.S.M., Zhang, Y.-Z., Huang, Y., Song, Z.Z., Chow, W.-N., Fan, R.Y.Y., Ahmed, S.S., Yeung, H.C., Lam, C.S.F., Cai, J.-P., Wong, S.S.Y., Chan, J.F.W., Yuen, K.-Y., Zhang, H.-L., Woo, P.C.Y. 2015. Severe acute respiratory syndrome (SARS) 
coronavirus ORF8 protein is acquired from SARSrelated coronavirus from greater horseshoe bats through recombination. J. Virol. 89, 10532-10547; doi:10.1128/jvi.01048-15.

Li, W., Zhang, C., Sui, J., Kuhn, J.H., Moore, M.J., Luo, S., Wong, S.K., Murakami, A. 2005. Receptor and viral determinants of SARS-coronavirus adaptation to human ACE2. EMBO J. 24, 1634-1643.

Li, X., Song, Y., Cui, J. 2020. Bat origin of a new human coronavirus: there and back again. Sci. China Life Sci. 63, 461-462; doi:10.1007/s11427-020-1645-7.

Lu, R., Zhao, X., Li, J., Niu, P., Yang, B., Wu, H., Wang, W., Song, H., Huang, B., Zhu, N., Bi, Y., Ma, X., Zhan, F., Wang, L., Hu, T., Zhou, H., Hu, Z., Zhou, W., Zhao, L., Chen, J., Meng, Y., Wang, J., Lin, Y., Yuan, J., Xie, Z., Ma, J., Liu, W.J., Wang, D., Xu, W., Holmes, E.C., Gao, G.F., Wu, G., Chen, W., Shi, W., Tan, W. 2020. Genomic characterisation and epidemiology of 2019 novel coronavirus: implications for virus origins and receptor binding. Lancet 395, 565-574; doi:10.1016/S01406736(20)30251-8.

Luk, H.K.H., Li, X., Fung, J., Lau, S.K.P., Woo, P.C.Y. 2019. Molecular epidemiology, evolution and phylogeny of SARS coronavirus. Infect. Genet. Evol. 71, 21-30; doi:10.1016/j.meegid.2019.03.001.

Luo, C.-M., Wang, N., Yang, X.-L., Liu, H.-Z., Zhang, W., Li, B., Hu, B., Peng, C., Geng, Q.-B., Zhu, G.J., Li, F., Shi, Z.-L. 2018. Discovery of novel bat coronaviruses in South China that use the same receptor as middle east respiratory syndrome coronavirus. J. Virol. 92, e00116-18; doi:10.1128/ jvi.00116-18.

Mackay, I.M., Arden, K.E. 2015. MERS coronavirus: diagnostics, epidemiology and transmission. Virol. J. 12, 222; doi:10.1186/s12985-015-0439-5.

Mallapaty, S. 2020a. Cats can get coronavirus, study suggests-but pet owners need not panic. Nat. Mag. Available via https://www.scientificamerican.com/ article/cats-can-get-coronavirus-study-suggestsbut-pet-owners-need-not-panic/ (Accessed 7 April 2020).

Mallapaty, S. 2020b. Coronavirus can infect cats dogs, not so much. Nature. Available via https:// www.nature.com/articles/d41586-020-00984-8 (Accessed 17 April 2020).

Martina, B.E.E., Haagmans, B.L., Kuiken, T., Fouchier, R.A.M., Rimmelzwaan, G.F., Van Amerongen, G., Peiris, J.S.M., Lim, W., Osterhaus, A.D.M.E. 2003. SARS virus infection of cats and ferrets. Nature 425, 915; doi:10.1038/425915a.

Memish, Z.A., Mishra, N., Olival, K.J., Fagbo, S.F., Kapoor, V., Epstein, J.H., AlHakeem, R., Al Asmari, M., Islam, A., Kapoor, A., Briese, T., Daszak, P., Al Rabeeah, A.A., Lipkin, W.I. 2013. Middle East respiratory syndrome coronavirus in Bats,
Saudi Arabia. Emerg. Infect. Dis. 19, 1819-1823; doi:10.3201/eid1911.131172.

Mohd, H.A., Al-tawfiq, J.A., Memish, Z.A. 2016. Middle east respiratory syndrome coronavirus (MERS-CoV) origin and animal reservoir. Virol. J. 13, 87; doi:10.1186/s12985-016-0544-0.

Munster, V.J., de Wit, E., Feldmann, H. 2013. Pneumonia from human coronavirus in a macaque model. N. Engl. J. Med. 368, 1560-1562; doi:10.1056/ NEJMc1302436.

Nowotny, N., Kolodziejek, J. 2014. Middle East respiratory syndrome coronavirus (MERS$\mathrm{CoV}$ ) in dromedary camels, Oman, 2013. Euro Surveill. 19, 29781; doi:10.2807/1560-7917. ES2014.19.16.20781.

Peeri, N., Bibi, S., Rahman, M.S., Mehdi, B. 2020. The SARS, MERS and novel coronavirus (COVID-19) epidemics, the newest and biggest global health threats: what lessons have we learned? Int. J. Epidemiol. pii: dyaa033. doi:10.1093/ije/dyaa033.

Reusken, C.B.E.M., Haagmans, B.L., Müller, M.A., Gutierrez, C., Godeke, G.J., Meyer, B., Muth, D., Raj, V.S., Vries, L.S. De, Corman, V.M., Drexler, J.F., Smits, S.L., El Tahir, Y.E., De Sousa, R., van Beek, J., Nowotny, N., van Maanen, K., HidalgoHermoso, E., Bosch, B.J., Rottier, P., Osterhaus, A., Gortázar-Schmidt, C., Drosten, C., Koopmans, M.P.G. 2013. Middle East respiratory syndrome coronavirus neutralising serum antibodies in dromedary camels: a comparative serological study. Lancet Infect. Dis. 13, 859-866; doi:10.1016/ S1473-3099(13)70164-6.

Roberts, A., Lamirande, E.W., Vogel, L., Jackson, J.P., Paddock, C.D., Guarner, J., Zaki, S.R., Sheahan, T., Baric, R., Subbarao, K. 2008. Animal models and vaccines for SARS-CoV infection. Virus Res. 133, 20-32; doi:10.1016/j.virusres.2007.03.025.

Seah, I., Agrawal, R. 2020. Can the coronavirus disease 2019 (COVID-19) affect the eyes? A review of coronaviruses and ocular implications in humans and animals. Ocul. Immunol. Inflamm. 28(3), 1-5; doi:10.1080/09273948.2020.1738501.

Shi, J., Wen, Z., Zhong, G., Yang, H., Wang, C., Huang, B., Liu, R., He, X., Shuai, L., Sun, Z., Zhao, Y., Liu, P., Liang, L., Cui, P., Wang, J., Zhang, X., Guan, Y., Tan, W., Wu, G., Chen, H., Bu, Z. 2020. Susceptibility of ferrets, cats, dogs, and different domestic animals to SARS-coronavirus-2. Science. pii: eabb7015.

Smits, S.L., De Lang, A., Van Den Brand, J.M.A., Leijten, L.M., Van Ijcken, W.F., Eijkemans, M.J.C., Van Amerongen, G., Kuiken, T., Andeweg, A.C., Osterhaus, A.D.M.E., Haagmans, B.L. 2010. Exacerbated innate host response to SARS-CoV in aged non-human primates. PLoS Pathog. 6, e1000756; doi:10.1371/journal.ppat.1000756. 
Smits, S.L., van den Brand, J.M.A., de Lang, A., Leijten, L.M.E., van IJcken, W.F., van Amerongen, G., Osterhaus, A.D.M.E., Andeweg, A.C., Haagmans, B.L. 2011. Distinct severe acute respiratory syndrome coronavirus-induced acute lung injury pathways in two different nonhuman primate species. J. Virol. 85, 4234-4245; doi:10.1128/ jvi.02395-10.

Sun, J., He, W., Wang, L., Lai, A., Ji, X., Zhai, X., Li, G., Suchard, M.A., Tian, J., Zhou, J., Veit, M., Su, S. 2020. COVID-19 : epidemiology, evolution, and cross-disciplinary perspectives. Trends Mol. Med. 26, 483-495; doi:10.1016/j.molmed.2020.02.008.

Tang, X., Wu, C., Li, X., Song, Y., Yao, X., Wu, X., Duan, Y., Zhang, H., Wang, Y., Qian, Z., Cui, J., Lu, J. 2020. On the origin and continuing evolution of SARS-CoV-2. Natl. Sci. Rev.

Valitutto, M., Aung, O., Tun, K., Vodzak, M.E., Zimmerman, D., Yu, J., Win, Y.T., Maw, M.T., Thein, W.Z., Win, H., Dhanota, J., Ontiveros, V., Smith, B., Tremeau-Brevard, A., Goldstein, T., Johnson, C.K., Murray, S., Mazet, J. 2020. Detection of novel coronaviruses in bats in Myanmar. PLoS One 15, e0230802; doi:10.1371/journal.pone.0230802.

Vergara-Alert, J., Raj, V.S., Muñoz, M., Abad, F.X., Cordón, I., Haagmans, B.L., Bensaid, A., Segalés, J. 2017b. Middle East respiratory syndrome coronavirus experimental transmission using a pig model. Transbound. Emerg. Dis. 64, 1342-1345; doi:10.1111/tbed.12668.

Vergara-Alert, Júlia, van den Brand, J.M.A., Widagdo, W., Muñoz, M., Raj, V.S., Schipper, D., Solanes, D., Cordón, I., Bensaid, A., Haagmans, B.L., Segalés, J. 2017a. Livestock susceptibility to infection with middle east respiratory syndrome coronavirus. Emerg. Infect. Dis. 23, 232-240; doi:10.3201/ eid2302.161239.

Wang, M., Jing, H., Xu, H., Jiang, X., Kan, B., Liu, Q., Wan, K., Cui, B., Zheng, H., Cui, Z., Yan, M., Liang, W., Wang, H., Qi, X., Li, Z., Li, M., Chen, K., Zhang, E., Zhang, S., Hai, R., Yu, D., Xu, J. 2005. Surveillance on severe acute respiratory syndrome associated coronavirus in animals at a live animal market of Guangzhou in 2004. Zhonghua Liu Xing Bing Xue Za Zhi 26, 84-87.

Wang, Y, Liu, D., Shi, W., Lu, R., Wang, W., Zhao, Y., Deng, Y., Zhou, W., Ren, H., Wu, J., Wang, Yu, Wu, G., Gao, G.F., Tan, W. 2015. Origin and possible genetic recombination of the middle east respiratory syndrome coronavirus from the first imported case in China : phylogenetics and coalescence analysis. MBio 6, e01280-15; doi:10.1128/mBio.01280-15. Editor.

WHO, 2020. Coronavirus disease 2019 (COVID-19) Situation report-88. Available via https://www.who. $\mathrm{int} /$ docs/default-source/coronaviruse/situationreports/20200417-sitrep-88-covid-191b6cccd94f8 b4f219377bff55719a6ed.pdf?sfvrsn=ebe78315 6 (Accessed 18 April 2020).

Widagdo, W., Okba, N.M.A., Richard, M., De Meulder, D., Bestebroer, T.M., Lexmond, P., Farag, E.A.B.A., Al-Hajri, M., Stittelaar, K.J., De Waal, L., Van Amerongen, G., Van Den Brand, J.M.A., Haagmans, B.L., Herfst, S. 2019. Lack of middle east respiratory syndrome coronavirus transmission in rabbits. Viruses 11, 381; doi:10.3390/v11040381.

Woo, P.C.Y., Lau, S.K.P., Lam, C.S.F., Lau, C.C.Y., Tsang, A.K.L., Lau, J.H.N., Bai, R., Teng, J.L.L., Tsang, C.C.C., Wang, M., Zheng, B., Chan, K., Yuen, K. 2012. Discovery of seven novel mammalian and avian coronaviruses in the genus deltacoronavirus supports bat coronaviruses as the gene source of alphacoronavirus and betacoronavirus and avian coronaviruses as the gene source of gammacoronavirus and deltacoronavirus. J. Virol. 86, 3995-4008; doi:10.1128/JVI.06540-11.

Wu, A., Peng, Y., Huang, B., Ding, X., Wang, X., Niu, P., Meng, J., Zhu, Z., Zhang, Z., Wang, J., Sheng, J., Quan, L., Xia, Z., Tan, W., Cheng, G., Jiang, T., 2020. Genome composition and divergence of the novel coronavirus (2019-nCoV) originating in China. Cell Host Microbe 27, 328; doi:10.1016/j. chom.2020.02.001.

Xu, L., Zhang, F., Yang, W., Jiang, T., Lu, G., He, B., Li, X., Hu, T., Chen, G., Feng, Y., Zhang, Y., Fan, Q., Feng, J., Zhang, H., Tu, C. 2016. Detection and characterization of diverse alpha- and betacoronaviruses from bats in China. Virol. Sin. 31, 69-77; doi:10.1007/s12250-016-3727-3.

Xu, X., Chen, P., Wang, J., Feng, J., Zhou, H., Li, X., Zhong, W., Hao, P. 2020. Evolution of the novel coronavirus from the ongoing Wuhan outbreak and modeling of its spike protein for risk of human transmission. Sci. China Life Sci. 63, 457-460.

Yang, Y., Du, L., Liu, C., Wang, L., Tang, J., Baric, R.S., Jiang, S., Li, F. 2014. Receptor usage and cell entry of bat coronavirus HKU4 provide insight into batto-human transmission of MERS coronavirus. Proc. Natl. Acad. Sci. 111, 12516-12521; doi:10.1073/ pnas. 1405889111

Yang, Y., Liu, C., Du, L., Jiang, S., Shi, Z., Baric, R.S., Li, F. 2015. Two mutations were critical for batto-human transmission of Middle East respiratory syndrome coromavirus. J. Virol. 89, 9119-9123; doi:10.1128/JVI.01279-15.

Zaki, A.M., Van Boheemen, S., Bestebroer, T.M., Osterhaus, A.D., Fouchier, R.A. 2012. Isolation of a novel coronavirus from a man with pneumonia in Saudi Arabia. N. Engl. J. Med. 367, 1814-1820; doi:10.1056/NEJMoa1211721.

Zhang, T., Wu, Q., Zhang, Z., 2020. Probable pangolin origin of SARS-CoV-2 associated with the COVID-19 outbreak. Curr. Biol. 30, 1346-1351; doi:10.1016/j.cub.2020.03.022. 
Zhou, P., Yang, X. Lou, Wang, X.G., Hu, B., Zhang, L., Zhang, W., Si, H.R., Zhu, Y., Li, B., Huang, C.L., Chen, H.D., Chen, J., Luo, Y., Guo, H., Jiang, R. Di, Liu, M.Q., Chen, Y., Shen, X.R., Wang, X., Zheng, X.S., Zhao, K., Chen, Q.J., Deng, F., Liu, L.L.,
Yan, B., Zhan, F.X., Wang, Y.Y., Xiao, G.F., Shi, Z.L. 2020. A pneumonia outbreak associated with a new coronavirus of probable bat origin. Nature 579, 270-273; doi:10.1038/s41586-020-2012-7. 